\title{
Occurrence of Clostridium spp. in ewe's milk: enumeration and identification of isolates
}

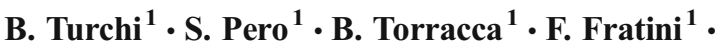 \\ S. Mancini $^{1}$ - A. Galiero ${ }^{1} \cdot$ F. Pedonese ${ }^{1}$. \\ R. Nuvoloni ${ }^{1} \cdot$ D. Cerri $^{1}$
}

Received: 2 February 2016 / Revised: 14 June 2016 / Accepted: 20 June 2016 /

Published online: 20 July 2016

(C) INRA and Springer-Verlag France 2016

\begin{abstract}
The presence of gas-producing clostridia in ewe's milk can lead to the occurrence of late-blowing defects in cheeses. However, data on this aspect are limited. In the present study, using the most probable number (MPN) method, clostridial spores were enumerated in 527 ewe's milk samples collected in the Grosseto Province (Tuscany, Italy) from autumn 2014 to summer 2015. In addition, using polymerase chain reaction (PCR), we identified the species most frequently involved in lateblowing defects in cheese (Clostridium tyrobutyricum, Clostridium butyricum, Clostridium beijerinckii, and Clostridium sporogenes), and of Clostridium perfringens. Gas-producing clostridial spores were detected in $99 \%$ of samples. Spore concentrations ranged from 360 to more than 110,000 spores $\cdot \mathrm{L}^{-1}$. We observed that $86 \%$ of samples had a spore load higher than 1000 spores $\cdot \mathrm{L}^{-1}$. During autumn and summer, spore concentrations were significantly higher than in winter and spring $(P<0.001)$. A total of 222 isolates obtained from 77 MPN positive tubes from different milk samples were subjected to PCR. Colonies from 63/77 (82\%) MPN positive tubes were taxonomically identified. Among the 63 PCR-positive samples, C. perfringens was the most frequently detected species (56\%), followed by C. sporogenes (44\%), C. tyrobutyricum (7.9\%), C. butyricum (1.6\%), and C. beijerinkii (1.6\%). In addition, in $11 \%$ of the MPN positive tubes, at least two clostridial species were found to be present simultaneously. This work highlights the presence of clostridial spores in ovine milk from central Italy (Tuscany) and led to the identification of some of the clostridia species involved in such high spore loads.
\end{abstract}

Keywords Gas-producing Clostridium spp. · Ewe's milk, clostridial spores · Enumeration · Identification

B. Turchi

barbara.turchi@unipi.it

1 Department of Veterinary Sciences, University of Pisa, Viale delle Piagge 2, Pisa, Italy 


\section{Introduction}

The presence of clostridial spores in ewe's milk could represent an emerging problem due to several factors related to climate and herd management changes. In particular, the increasing number of wolves (Canis lupus) in central Italy (Bassi et al. 2015b; Vitali 2014) has led to an increase in semi-extensive farming, with an increased use of fenced pastures and housing facilities, which promote the spread and concentration of environmental spores, especially when the bedding is not managed appropriately. In this regard, in some areas of Spain and France, a ewe's milk quality payment system has been adopted in order to promote farm management practices that are effective in reducing the clostridial spores load of the milk. A maximum limit of $1000-1300$ spores $\cdot \mathrm{L}^{-1}$ has been established (Pirisi et al. 2007).

Despite the fact that not only bovine milk cheeses but also ewe's milk cheeses can be affected by late-blowing defects (Gómez-Torres et al. 2015), little is known regarding the occurrence of clostridial spores in ewe's milk. Indeed, the current literature regarding the presence and relevance of clostridia spores in Italian ewe's milk is limited (Scintu et al. 2004). However, a few surveys carried out in Spain are available (Garde et al. 2011; Arias et al. 2013; Gómez-Torres et al. 2015). Concerning data from reports analyzing milk samples for the production of Manchego cheese in Spain, Garde et al. (2011) detected lactate-fermenting clostridial spores in $97 \%$ of samples. Despite these data, these authors also reported a low annual incidence $(0.28 \%)$ of late-blowing defects in Manchego cheese and ascribed this result to the use of lysozyme in cheese manufacturing. In fact, lysozyme can reduce late-blowing especially when the spore concentration is lower than $500 \mathrm{~L}^{-1}$. However, some drawbacks have been reported, such as its allergenicity and the variable degree of susceptibility of the spores (Brändle et al., 2016). In addition, Garde et al. (2011) observed the highest mean milk spore count in the summer $\left(26,800\right.$ spores $\left.\cdot \mathrm{L}^{-1}\right)$, with $C$. sporogenes as the most abundant species in cheeses with late-blowing defects. This is in accordance with Arias et al. (2013), who also found that $C$. sporogenes was the most commonly isolated species, followed by C. beijerinkii and C. tyrobutyricum. Arias et al. (2013) also highlighted that the use of farm-made forage and wet brewer grain as animal feed, as well as the presence of dust in the milking parlor, favors the presence of Clostridium spp. spores in milk.

Recent studies have also highlighted the presence of Clostridium perfringens in raw milk and curds (Chaturvedi and Shukla 2015; Feligini et al. 2014). Since this species is able to produce gas from the metabolism of carbohydrates (Pigato et al. 2012), this could have an impact on the enumeration of gas-producing clostridia using the MPN method.

Our aim was to enumerate gas-producing clostridial spores in ewe's milk samples collected in the province of Grosseto (Tuscany, Italy) by the MPN method. An additional aim was to evaluate by PCR the presence of some of the clostridial species most frequently involved in the occurrence of late-blowing defects in cheeses (C. beijerinckii, C. butyricum, C. sporogenes, and C. tyrobutyricum), and of C. perfringens as well. 


\section{Materials and methods}

\subsection{Milk samples}

From autumn 2014 to summer 2015, 527 ewe's milk samples were obtained from four milk tankers (A-D) collecting milk from 95 sheep farms located in the province of Grosseto (Tuscany, Italy). The number of milk samples per season varied on the basis of the sheep lactation pattern and, thus, milk availability (Table 1). All tankers delivered milk to the same dairy plant, which reported problems related to late-blowing in cheeses. The four tankers collected milk from different areas of the province of Grosseto. Regarding the animal nutrition and feeding management, sheep were fed on pastures or alternatively on green fodder or hay produced from local meadows; concentrates were also employed to supplement the sheep diet when necessary.

\subsection{Enumeration of gas-producing Clostridium spp. spores}

Gas-producing clostridia spores were determined using the MPN method, as described by Weinzirl (1916) and modified by Annibaldi (1969). One milliliter of each milk sample was dispensed into $9 \mathrm{~mL}$ of sterile saline, and decimal dilutions (1:10-1:1000) were performed. Aliquots $(1 \mathrm{~mL})$ from serial dilutions were inoculated into three tube series containing $9 \mathrm{~mL}$ of UHT milk with $0.5 \mathrm{~mL}$ of Annibaldi solution ( $5 \mathrm{~g}$ sodium acetate trihydrate, $1 \mathrm{~g}$ L-cysteine, $5 \mathrm{~g}$ yeast extract, $16.8 \mathrm{~mL} 60 \% \mathrm{w} / \mathrm{w}$ sodium lactate, $100 \mathrm{~mL}$ distilled water). All the tubes were covered with $2 \mathrm{~cm}$ of sterile melted paraffin wax/liquid paraffin mixture $(1: 2 \mathrm{v} / \mathrm{v})$ and heated at $80{ }^{\circ} \mathrm{C}$ for $10 \mathrm{~min}$. Incubation was carried out at $37{ }^{\circ} \mathrm{C}$ for 7 days. MPN counts were expressed as spores $\mathrm{L}^{-1}$.

\subsection{Isolation and purification of gas-producing clostridia}

A drop of culture was collected from 77 MPN gas positive tubes and streaked on Reinforced Clostridial Agar (RCA) (Oxoid, Milan, Italy). The plates were incubated at $37^{\circ} \mathrm{C}$ for 3 days in anaerobiosis. On the basis of different colony morphologies, one to five colonies were randomly picked from each plate and purified by streaking them on $\mathrm{RCA}$ at least three times $\left(37^{\circ} \mathrm{C}\right.$ for 3 days, anaerobiosis). DNA was extracted from purified colonies.

Table 1 Number of milk samples collected for each milk tanker and season

\begin{tabular}{|c|c|c|c|c|c|c|c|}
\hline & Milk tankers & Farms & Autumn & Winter & Spring & Summer & Total \\
\hline & A & 15 & 21 & 42 & 36 & 16 & 115 \\
\hline & $\mathrm{B}$ & 30 & 12 & 54 & 44 & 21 & 131 \\
\hline & $\mathrm{C}$ & 25 & 20 & 79 & 47 & 16 & 162 \\
\hline & $\mathrm{D}$ & 25 & 16 & 41 & 47 & 15 & 119 \\
\hline Total & & & 69 & 216 & 174 & 68 & 527 \\
\hline
\end{tabular}




\subsection{DNA extraction and identification of Clostridium spp. isolates}

DNA extraction was performed by the boiling method according to Arias et al. (2013). Colonies from purified cultures were collected and suspended in $100 \mu \mathrm{L}$ of sterile distilled water. The suspension was subjected to $95{ }^{\circ} \mathrm{C}$ for $10 \mathrm{~min}$ in order to break up the cells. The suspension was then centrifuged at $9700 \times \mathrm{g}$ for $15 \mathrm{~s}$ and the supernatant was used for the isolates identification.

C. beijerinckii, C. butyricum, C. sporogenes, and C. tyrobutyricum were identified by multiplex PCR according to Cremonesi et al. (2012). All isolates negative in the multiplex PCR were subjected to a simplex PCR assay for the identification of C. perfringens according to Kikuchi et al. (2002).

\subsection{Statistical analysis}

All statistical analyses were performed with R v.3.2.3 (R Foundation for Statistical Computing, Vienna, Austria) and differences were considered significant if associated with a $P<0.05$.

For statistical analyses, non-parametrical tests were employed, since spore count data were not normally distributed. For MPN results $>110,000$ spores $\mathrm{L}^{-1}$, the value 110,000 was used for statistical calculations. The statistical significance of differences in spore counts among groups was tested with the Kruskal-Wallis test using tankers or seasons as a factor. Pairwise comparisons were then performed with the Wilcoxon test.

\section{Results}

\subsection{Enumeration of gas-producing Clostridium spp. spores}

Gas-producing clostridial spores were detected in $99 \%$ of the 527 analyzed milk samples from the four milk tankers. Among these samples, $86 \%$ resulted in spore concentrations higher than the threshold of 1000 spores $\cdot \mathrm{L}^{-1}$ indicated by Pirisi et al. (2007). In particular, the spore concentrations ranged from 360 to more than 110,000 spores $\cdot \mathrm{L}^{-1}$. Following statistical analysis, no significant difference was found among the spore load of samples from the four milk tankers. Considering the difference in the spore load among the different seasons, in autumn and summer MPN mean counts were significantly higher than in winter and spring $(P<0.001)$ (Fig. 1). For all seasons, except autumn, the 1000-5000 spores $\cdot \mathrm{L}^{-1}$ was the category most represented (Fig. 2). This category included $51 \%$ (110/216) winter samples, $47 \%(82 / 174)$ spring samples and $48 \%(33 / 68)$ summer samples. The most represented category in autumn was 10,000-50,000 spores $\cdot \mathrm{L}^{-1}$, comprising $41 \%$ samples $(28 / 69)$.

\subsection{PCR identification of Clostridium spp. isolates}

The content of 77 MPN gas positive tubes from different milk samples was subcultured. Subsequently, DNA was extracted from 222 purified isolates. Multiplex PCR for the detection of $C$. beijerinckii, C. butyricum, C. sporogenes, and C. tyrobutyricum led to the identification of colonies from 34/77 MPN gas positive 


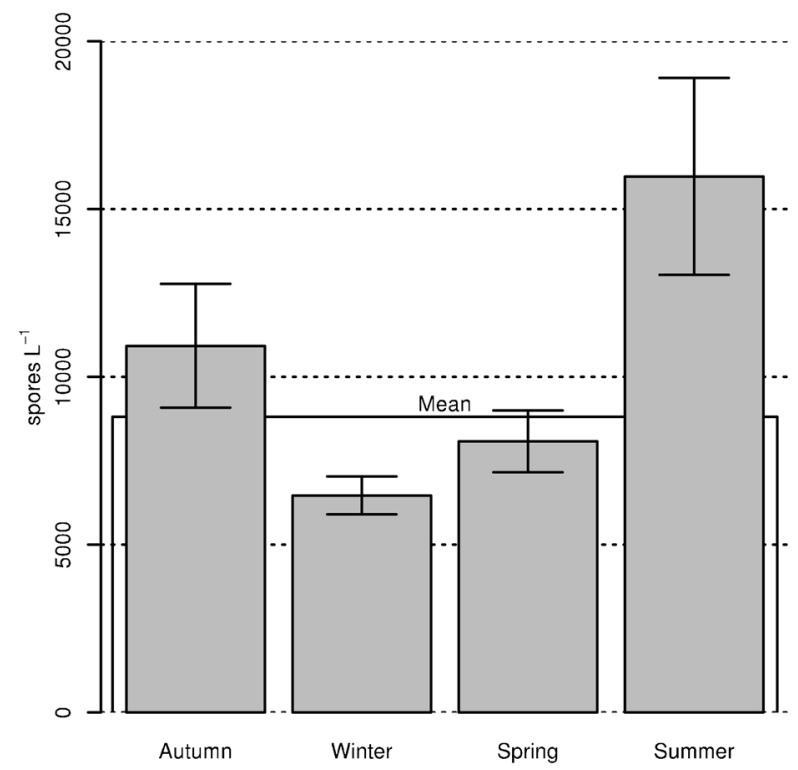

Fig. 1 Costridial spore counts (average and standard error) in raw ovine milk collected in Grosseto district (Tuscany, Italy) in different seasons

tubes (44\%). By simplex PCR, colonies belonging to $C$. perfringens were detected from 35/77 positive milk samples (45\%). Overall, multiplex and simplex PCR allowed the identification of one or more clostridia species from 63 out of the 77 (82\%) MPN positive tubes. Isolates originating from the same sample and belonging to the same species were considered as clones. Among the $63 \mathrm{MPN}$ tubes from where PCR positive isolates were obtained, 35/63 (56\%) showed the presence of C. perfringens, 28/63 (44\%) of C. sporogenes, 5/63 (7.9\%) of C. tyrobutyricum, 1/63 (1.6\%) of C. butyricum, and $1 / 63(1.6 \%)$ of $C$. beijerinkii. In addition, $7 / 63(11 \%)$ samples revealed the simultaneous presence of two clostridial species (Table 2).

\section{Discussion}

Our results revealed the presence of clostridial spores in tested ewe's milk samples. Gas-producing clostridia were found in $99 \%$ of the 527 ewe's milk samples analyzed. This is in accordance with Garde et al. (2011), who also reported a high percentage of positive ewe's milk samples (97\%). Spore numbers detected ranged from 360 up to $>110,000$ spores $\mathrm{L}^{-1}$. The maximum concentration was higher than that reported in Italy by Scintu et al. (2004) (1072 spores $\cdot \mathrm{L}^{-1}$ ), but comparable to that reported in Spain by Garde et al. (2011) (240,000 spores $\left.\mathrm{L}^{-1}\right)$. Also, in accordance with Garde et al. (2011), the majority of the samples analyzed (65\%) (345/527) had MPN counts ranging from 1000 to 10,000 spores $\mathrm{L}^{-1}$.

With regard to the variability among seasons, samples collected in autumn and summer showed significantly higher MPN counts than those collected in winter and spring $(P<0.001)$. These results are consistent with those reported by Garde et al. (2011), who obtained significantly higher MPN counts in summer than in winter 
autumn
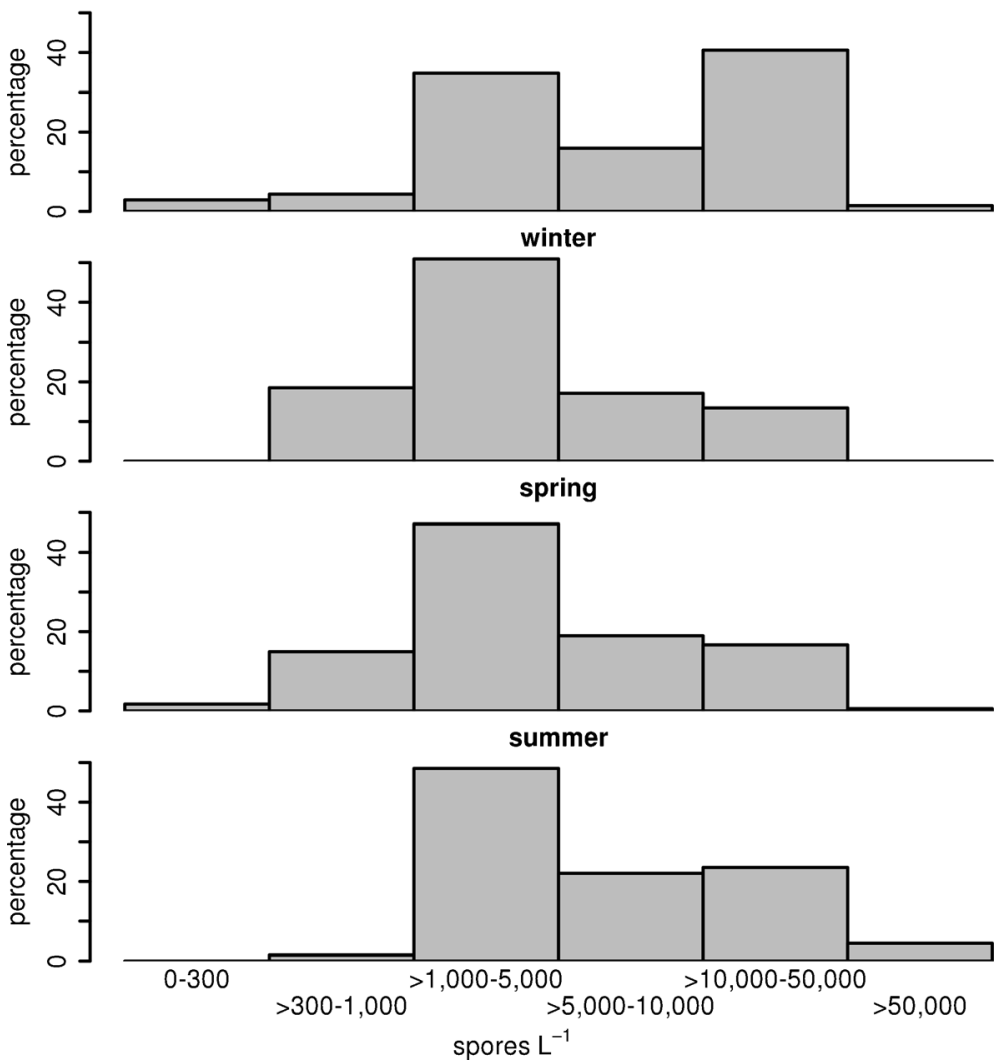

Fig. 2 Clostridial spore counts (spores $\mathrm{L}^{-1}$ ) of analyzed ovine milk samples. Relative frequencies $(\%)$ of different spore count intervals for each season

Table 2 Number and percentage of positive milk samples for each clostridial species (Clostridium beijerinckii, Clostridium butyricum, Clostridium sporogenes, Clostridium tyrobutyricum, and Clostridium perfringens) and clostridial species associations among the 63 PCR positive milk samples

\begin{tabular}{lcc}
\hline & Number of positive samples & Percentage $(\%)$ \\
\hline C. perfringens & $35 / 63$ & 56 \\
C. sporogenes & $28 / 63$ & 44 \\
C. tyrobutyricum & $5 / 63$ & 7.9 \\
C. butyricum & $1 / 63$ & 1.6 \\
C. beijerinkii & $1 / 63$ & 1.6 \\
C. sporogenes/C. perfringens & $4 / 63$ & 6.4 \\
C. tyrobutyricum/C. perfringens & $1 / 63$ & 1.6 \\
C. butyricum/C. perfringens & $1 / 63$ & 1.6 \\
C. tyrobutyricum/C. sporogenes & $1 / 63$ & 1.6 \\
\hline
\end{tabular}


$(P<0.001)$. However, they also detected higher values in winter than in autumn and spring. Again, in accordance with our study, Scintu et al. (2004) reported significantly higher MPN spore counts in summer than in other seasons. However, it is important to mention that the variability among seasons observed in the present study could have been also influenced by the variability of milk sample numbers analyzed in different seasons.

All together, these results highlight some differences between cow's and ewe's milk, when clostridia contamination is considered. Indeed, while for cow's milk, high clostridial spore counts are mainly recorded in winter, due to silage feeding (Driehuis 2013; Zucali et al. 2015), for ewe's milk, high MPN counts have also been observed in summer. This could be due to environmental factors, husbandry and feeding practices other than silage feeding, such as wool spore contamination, milking hygiene, and an incorrect management of the bedding, especially during anomalous summer seasons (i.e., particularly rainy or dry). In the farms from where the milk analyzed in this work was collected, silage was not fed to the animals, either in winter or in other seasons. In fact, the sheep were fed on pastures or alternatively on green fodder or hay produced from local meadows.

In the geographical area where our study took place, shelters and fenced pastures are used to prevent attacks by wolves, which could result in sheep staying for longer periods of time in a confined space, and consequently in an environment with a higher clostridia spore concentration.

In this study, bulk milk tanker samples were analyzed, whereas a direct correlation between high spore counts and farming practices would require the analysis of milk samples from individual farms and a detailed survey of farming practices. On the other hand, the fact that no statistical difference was found among milk tankers, each serving a different geographical area, suggests that the high clostridial contamination was not limited to an individual farm or a single area. Moreover, from the dairy plant point of view, the occurrence of late-blowing defects in cheeses is related to the spore count of the bulk milk used for cheese manufacturing. However, to solve the root of the problem, it would be necessary to trace the high spore contamination back to the individual farms.

Spores belonging to some of the clostridial species most frequently involved in the occurrence of late-blowing defects in cheese (C. tyrobutyricum, C. sporogenes, C. butyricum, C. beijerinckii) were detected in the milk samples. As previously reported by other authors (Chaturvedi and Shukla 2015; Feligini et al. 2014), C. perfringens spores were also detected.

In accordance with Arias et al. (2013), among the classical butyric acid producing clostridial species, C. sporogenes was the most frequently detected. In addition, C. perfringens was identified in more than $40 \%$ of MPN positive tubes analyzed, thus being the most frequently detected clostridial species from the samples analyzed. Currently, only a few reports are available on the presence of $C$. perfringens in milk produced in Italy (Feligini et al. 2014; Pigato et al. 2012) and none of them have focused on ewe's milk. Feligini et al. (2014) reported a $C$. perfringens incidence of $98.7 \%$ (spores and vegetative cells) in milk samples analyzed, while Pigato et al. (2012) reported 25.6\% (spores). Fortunately, C. perfringens food disease risks associated with the consumption of milk and dairy products is negligible (De Buyser et al. 2001). This could be related to the inability of $C$. perfringens spores to germinate and replicate in milk or cheese in order to reach a vegetative cell concentration sufficient to cause illness $\left(10^{8}\right.$ vegetative cells of enterotoxins producing strain per gram or milliliter) (Bassi et al. 2015a).

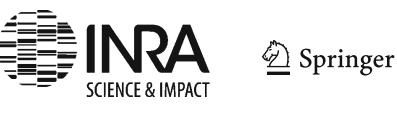


The importance of considering the presence of $C$. perfringens in milk samples is related to its ability to produce gas through lactate fermentation (Pigato et al. 2012), which could contribute to the occurrence of late-blowing defects, although no evidence of this correlation has been provided to date. In any case, since $C$. perfringens is able to grow in the media used for the enumeration of butyric acid producing clostridia and produces a notable amount of gas in a short time period (Pigato et al. 2012), its presence could lead to an overestimation of the number of gas-producing clostridia spores in milk.

The correlation between the MPN spore counts and the incidence of lateblowing defects in ewe's milk cheeses also needs to be clarified. Similarly to Garde et al. (2011), the annual occurrence of late-blowing defects observed at the dairy plant involved in our study was only $1 \%$ (data not shown). At the same time, $86 \%$ of the analyzed milk samples had a spore load higher than the threshold of 1000 spores $\cdot \mathrm{L}^{-1}$. This could also be due to the use of cultural media, which are not selective for butyric-acid-producing clostridia, but also allow the growth of other gas-producing clostridia, such as $C$. perfringens. Thus, the role of $C$. perfringens in late-blowing needs to be clarified, also taking into account that it can be isolated from raw milk and cheeses (Bassi et al. 2015a; Chaturvedi and Shukla 2015; Feligini et al. 2014).

\section{Conclusions}

The present work contributes to increasing the knowledge of clostridia contamination in ewe's milk in central Italy (Tuscany), in particular with regard to spore concentration and to the identification of some of the clostridial species most frequently involved in late-blowing defects.

The MPN analysis performed showed that $99 \%$ of the samples were positive for gasproducing clostridia and that $86 \%$ of the positive samples presented a concentration of spores higher than 1000 spores $\mathrm{L}^{-1}$. These results could be ascribed to several factors, such as a milder and more humid autumn and winter, and the increased use of animal shelters to protect against wolves, which together could result in an increase of the spore concentration in milk.

Further studies are needed in order to better evaluate the importance of clostridial contamination in ewe's milk and the role of different clostridial species in the occurrence of late-blowing defects in cheeses.

\section{Compliance with ethical standards}

Conflict of interest The authors declare that they have no conflict of interest.

\section{References}

Annibaldi S (1969) Modificazione della prova di Weinzirl per la ricerca dei clostridi butirrici nel latte. Scienza e Tecnica Lattiero-Casearia 20:75-79

Arias C, Oliete B, Seseña S, Jimenez L, Pérez-Guzmán MD, Arias R (2013) Importance of on-farm management practices on lactate-fermenting Clostridium spp. spore contamination of Manchega ewe 
milk: determination of risk factors and characterization of Clostridium population. Small Rumin Res 111: $120-128$

Bassi D, Puglisi E, Cocconcelli PS (2015a) Understanding the bacterial communities of hard cheese with blowing defect. Food Microbiol 52:106-118

Bassi E, Willis SG, Passilongo D, Mattioli L, Apollonio M (2015b) Predicting the spatial distribution of wolf (Canis lupus) breeding areas in a mountainous region of Central Italy. PLoS One 10(6)

Brändle J, Domig KJ, Kneifel W (2016) Relevance and analysis of butyric acid producing clostridia in milk and cheese. Food Control 67:96-113

Chaturvedi A, Shukla S (2015) Occurrence of Clostridium species in different dairy products and its associated health risk. Int J Recent Sci Res 2:2827-2829

Cremonesi P, Vanoni L, Silvetti T, Morandi S, Brasca M (2012) Identification of Clostridium beijerinckii, Cl. butyricum, $\mathrm{Cl}$. sporogenes, $\mathrm{Cl}$. tyrobutyricum isolated from silage, raw milk and hard cheese by a multiplex PCR assay. J Dairy Res 79:318-323

De Buyser ML, Dufour B, Maire M, Lafarge V (2001) Implication of milk and milk products in food-borne diseases in France and in different industrialised countries. Int J Food Microbiol 67(1):1-17

Driehuis F (2013) Silage and the safety and quality of dairy foods: a review. Agric Food Sci 22(1):16-34

Feligini M, Brambati E, Panelli S, Ghitti M, Sacchi R, Capelli E, Bonacina C (2014) One-year investigation of Clostridium spp. occurrence in raw milk and curd of Grana Padano cheese by the automated ribosomal intergenic spacer analysis. Food Control 42:71-77

Garde S, Arias R, Gaya P, Nuñez M (2011) Occurrence of Clostridium spp. in ovine milk and Manchego cheese with late blowing defect: identification and characterization of isolates. Int Dairy J 21:272-278

Gómez-Torres N, Garde S, Peirotén Á, Ávila M (2015) Impact of Clostridium spp. on cheese characteristics: microbiology, color, formation of volatile compounds and off-flavors. Food Control 56:186-194

Kikuchi E, Miyamoto Y, Narushima S, Itoh K (2002) Design of species-specific primers to identify 13 species of Clostridium harbored in human intestinal tracts. Microbiol Immunol 46(5):353-358

Pigato S, Andrighetto C, Lombardi A (2012) Biodiversità di clostridi isolati dal latte. Scienza e Tecnica Lattiero-Casearia 63(3-4):171-178

Pirisi A, Lauret A, Dubeuf JP (2007) Basic and incentive payments for goat and sheep milk in relation to quality. Small Rumin Res 68:167-178

Scintu M, Mannu L, Caria A (2004) Presence of spores of Clostridium spp. in ewes' raw milk. Special issue of the International Dairy Federation, Zaragoza (Spain) 187-188

Vitali C (2014) A frame-analytical perspective on conflict between people and an expanding wolf Canis lupus population in central Italy. Oryx 48(04):575-583

Weinzirl J (1916) A simple test for C. sporogenes in milk and in water. Zentralblatt für Bakteriologie, 45:392

Zucali M, Bava L, Colombini S, Brasca M, Decimo M, Morandi S, Tamburini A, Crovetto GM (2015) Management practices and forage quality affecting the contamination of milk with anaerobic sporeforming bacteria. J Sci Food Agric 95(6):1294-1302 